\title{
Traditional or contemporary weather and climate forecasts: reaching Pacific communities
}

\author{
Lynda Chambers $^{1} \cdot$ Siosinamele Lui $^{2} \cdot$ Roan Plotz $^{1,3} \cdot$ David Hiriasia $^{4} \cdot$ Philip Malsale $^{2,5} \cdot$ \\ Rossylynn Pulehetoa-Mitiepo ${ }^{6} \cdot$ Melinda Natapei $^{5} \cdot$ Noel Sanau $^{4} \cdot$ Mike Waiwai $^{5,7} \cdot$ Lloyd Tahani $^{4} \cdot$ Albert Willy $^{5}$. \\ Seluvaia Finaulahi ${ }^{8} \cdot$ Falosita Loloa $^{8} \cdot$ 'Ofa Fa'anunu $^{8}$
}

Received: 20 August 2018 / Accepted: 13 March 2019 / Published online: 28 March 2019

(C) The Author(s) 2019

\begin{abstract}
In most countries, weather and seasonal climate forecasts are available through national meteorological services (NMSs). However, uptake of NMS forecasts in remote Pacific communities can be limited, particularly those relating to expected impacts. To address this, NMSs need a clearer understanding of the types of information local communities currently use and how this information is received, to enable them to modify their products and their delivery to better meet community needs. Structured community interviews across four Pacific countries (Niue, Solomon Islands, Tonga and Vanuatu) were undertaken by NMSs and their incountry partners. These interviews highlighted that remote communities mainly relied on weather and climate forecasts based on traditional knowledge (TK) alone or in combination with contemporary (NMS) forecasts. Many who had access to both forecasts systems indicated that they only sourced contemporary forecasts in the lead up to and during extreme events, particularly cyclones, to assist their decision-making. Recent extreme events in the Pacific have shown that self-reliant communities, with knowledge of traditional ways of forecasting, and responding to climate extremes, experience several benefits including reduced social-economic disruption and lower than expected death rates, particularly when combined with contemporary warnings. Therefore, there is a need to better understand the role of local traditional knowledge-based forecasts and for NMSs to work towards improving the content and communication of their forecasts to enable communities to take advantage of all available forecast information. For effective risk reduction, warnings and responses should therefore complement contemporary forecasts, rather than replace, TK-based forecasts.
\end{abstract}

Editor: Jamie Pittock.

Electronic supplementary material The online version of this article (https://doi.org/10.1007/s10113-019-01487-7) contains supplementary material, which is available to authorized users.

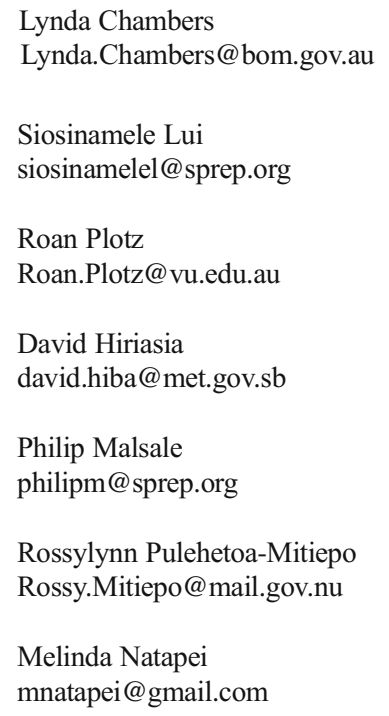

\author{
Noel Sanau \\ noel.sanau@met.gov.sb \\ Mike Waiwai \\ mwaiwai@vanuatu.gov.vu \\ Lloyd Tahani \\ 1.tahani@met.gov.sb \\ Albert Willy \\ s11044865@gmail.com \\ Seluvaia Finaulahi \\ seluf@met.gov.to \\ Falosita Loloa \\ falosital@met.gov.to \\ 'Ofa Fa'anunu \\ ofaf@met.gov.to
}

Extended author information available on the last page of the article 
Keywords Traditional knowledge $\cdot$ Indigenous knowledge $\cdot$ Seasonal forecast $\cdot$ Niue $\cdot$ Vanuatu $\cdot$ Solomon Islands $\cdot$ Tonga Pacific Islands

\section{Introduction}

Globally, remote communities are facing increased exposure to extreme weather events, and this is expected to add additional pressure on those already exposed to significant climate-related hazards and risks, including small island developing states in the Pacific (Nurse et al. 2014; Plotz and Chambers 2017; Malsale et al. 2018). By closely observing their local environment over many generations, local communities across the world have developed skills that increase their resilience to extreme weather and climate events, including tropical cyclones, floods and drought (Lefale 2010; Chand et al. 2014; Masinde 2015; Handmer and Iveson 2017; Plotz et al. 2017).

Traditional knowledge, also known as indigenous knowledge, is used here to refer to knowledge held by both indigenous and nonindigenous peoples living on the land; this knowledge can evolve over time (Malsale et al. 2018). Traditional weather and climate knowledge encompass a range of time scales, e.g. screeching kingfishers signifying imminent rain (Muse and Muse 1982) to abundant flowering of fruit trees indicating an active cyclone season (Chand et al. 2014). However, there are concerns over the loss of this knowledge, in part, through rapid urbanisation and an emphasis on western science and a reported changing reliability and loss of traditional indicators (Brahy 2006; King et al. 2008; Masinde 2015; Plotz et al. 2017).

In most countries, weather and seasonal climate forecasts are available through national meteorological services (NMSs). Although NMS forecasts are regularly produced, uptake of these contemporary forecasts and warnings is often limited in remote communities, with reasons for this including limited access, incomplete understanding or mistrust of forecasts, or because forecasts are not seen as location-specific by the communities (Lemos and Dilling 2007; Gilles and Valdivia 2009; Zuma-Netshiukhwi et al. 2013; Masinde 2015; Chengula and Nyambo 2017; Plotz et al. 2017).

For NMSs, to provide relevant and timely meteorological information to the communities they serve, they need a clearer understanding of the types of information local communities currently use, barriers to its use and how this information is received. Understanding these aspects will enable the NMSs to modify their products and communications to ensure that communities are well positioned to respond to climate variability and change. To this end, data collected by Pacific NMSs and their in-country partners was used to identify what types of forecasts are used by communities and the communication media used to obtain them. This information was used to explore similarities and differences between multiple communities in four countries with differing cultural backgrounds, geographies and governance systems (Malsale et al. 2018). Given the remoteness and strong cultural heritage of many communities, the emphasis was placed on the usage of traditional versus contemporary forecast systems.

Obtaining a better understanding on the usage and sources of weather and climate forecasts by Pacific Island communities was part of a wider project in the Pacific aiming to increase resilience to natural hazards (Chand et al. 2014; Chambers et al. 2017; Plotz et al. 2017; Malsale et al. 2018). This included the documentation of methods of traditional knowledge (TK) forecasting specifically related to weather and climate; determining how geographically widespread this knowledge was applied; if these forecasts had been impacted by environmental change (climate or land-use); development of ways to incorporate TK forecasts into routine NMS forecast products and producing improved climate communication products for local communities. Individual projects were led by the NMSs in four Pacific countries: Niue, Solomon Islands, Tonga and Vanuatu, with support provided under the Climate and Oceans Support Program in the Pacific, administered through the Australian Bureau of Meteorology and funded by the Department of Foreign Affairs and Trade.

In this study, we do not distinguish between weather and climate forecasts, rather we are concerned with the availability and use of forecasts from two main sources: contemporary (from the NMS) versus those based on traditional knowledge.

\section{Methods}

Each NMS identified primarily rural communities to interview on traditional weather and climate forecasting based on recommendations from in-country project partners. In Vanuatu, for example the communities were recommended by the Vanuatu Cultural Centre, the national institution responsible for the preservation, protection and promotion of the various aspects of culture within Vanuatu. A standardised interview form was developed and used by members of the NMS and their in-country partners, including representatives from the cultural centres (Chambers et al. 2017). Interviews were conducted from 2012 to 2017, with the form first trialled on Tanna Island, Vanuatu in 2012. All community consultations were guided by relevant protocols and partnerships specific to the communities, including obtaining permission to work within the communities (Malsale et al. 2018). Interviews were undertaken in local language by the NMSs and their in-country partners (e.g. Seuseu et al. 2013). The processes, including governance, surrounding this are described in Malsale et al. (2018) but importantly 
included prior informed consent and respect of cultural practices and information. For example, community meetings were held in Vanuatu and the Solomon Islands to brief communities on the project purpose, their role and expected community benefits before any interviews were conducted. Individuals were given the option to participate in the interviews. Additional TK holders (experts) were identified through recommendations from these participants. Although an effort was made to interview a variety of age groups, with a focus on those over 50 , and to get equal gender representation, this was not always achievable due to cultural protocols and other issues (see "Discussion" for further details).

While this study was concerned with forecast usage and sources, details on how TK forecasts are made was not part of the current study and, to respect cultural sensitivities, was not released to the authors, this information being retained securely within the respective countries. The information used in this analysis was based on a subset of the interview form (Supplementary Figs. S1 and S2) with responses de-identified, with names and addresses and traditional weather and climate knowledge narratives removed prior to compilation for analysis, i.e. the data was linked only to location, age category and gender.

NMSs and their partners conducted 254 interviews: 41 in Niue, 63 in the Solomon Islands, 36 in Tonga and 114 in Vanuatu (Table 1). However, only a subset of these interviews had complete forecast usage information, including the interviewee's age and gender, and these were used in subsequent analyses. NMSs in all countries travelled to as many remote communities as resources allowed (Table 1; Supplementary Table S1).

\section{Results}

The use of only contemporary NMS forecasts by communities was relatively small but similar across all countries surveyed (4.9\% Niue, 4.7\% Solomon Islands, 3.3\% Vanuatu and 14.0\% Tonga; Table 1). In contrast, sole reliance on TK forecasts differed between the countries, being highest in Vanuatu (43.3\% compared to $17.5 \%$ in the Solomon Islands, $12.2 \%$ in Niue and $2.8 \%$ in Tonga). In all countries, a high proportion of community members indicated that they used both TKbased and contemporary forecasts (70\% overall, $53 \%$ Vanuatu, $78 \%$ Solomon Islands, $82 \%$ Niue, $83 \%$ Tonga) to assist them in planning for weather and climate events. However, in the Tafea Province (Tanna Island) of Vanuatu, locals commented that contemporary forecasts were generally sought only when extreme events, such as cyclones or flooding, were expected.

The age breakdown of individuals interviewed varied between countries with the highest proportion of interviewees over 70 years of age in Niue (56\% compared to $41 \%$ in the Solomon Islands, $39 \%$ in Tonga and $12 \%$ in Vanuatu;
Table 1). However, in all countries but Tonga, individuals in this oldest age bracket relied on either TK only or on a combination of TK and contemporary forecasts, i.e. no individuals used only contemporary forecasts. In Tonga, 2 of 14 individuals over 70 relied solely on contemporary forecasts. The highest proportion of users of only NMSs forecasts were in the youngest age bracket (31-50 years of age).

Although an effort was made by the NMSs and their partners to interview both males and females, overall there was a bias towards more males being interviewed (75\%; Table 1). This was particularly noticeable in Vanuatu ( $90 \%$ of participants).

When receiving forecasts from outside sources, e.g. from the NMSs, this was predominantly via radio $(100 \%$ of those in Tonga, $93 \%$ in Solomon Islands, $74 \%$ in Vanuatu, $68 \%$ Niue), with other sources mentioned as newspapers (7\%) and via other people (including text messages, which accounted for $18 \%$ in Vanuatu). No participants in either the Solomon Islands or Vanuatu identified television or the Internet as a source of weather or climate forecasts, mostly likely due to local unavailability of these services. Whereas for Niue and Tonga, television (social media/Internet) used $73 \%(7 \%)$ and $25 \%(5 \%)$ of the time, respectively, to access forecast information.

\section{Discussion and conclusion}

Communities in the Pacific mainly relied on traditional weather and climate forecasts alone or in combination with NMS forecasts. Many who had access to both forecast systems indicated a preference for using TK-based forecasts except leading up to and during extreme weather events, particularly cyclones. During these times, they sourced additional information from the contemporary forecast systems to assist them in their decision-making, this behaviour was also observed in Fiji by Nalau et al. (2017).

Lower reliance on contemporary forecast products within the Pacific is likely, in part, related to ease of access and an uncomplete understanding of the information. For the more remote communities, communication media are limited, many relying on word-of-mouth, including phone calls or texts from family and friends in other locations and community networks, such as churches, area councils and men and women's groups (Noske-Turner et al. 2014). Communication mechanisms for forecast dissemination can be unreliable, with radio reception and mobile telephone reception being problematic in the outer islands and some rural areas (VMGD 2012; Noske-Turner et al. 2014; Handmer and Iveson 2017). This has also been reported elsewhere, including rural India (Lobo et al. 2017) and Tanzania (Chengula and Nyambo 2017). Spoken medium, such as radio, may be preferred by community members over television or newspapers, particularly as the main mechanism for teaching and learning is often oral (Lefale 2010; Walshe and Nunn 2012; Janif 2014). Similar results have been found for 
Table 1 Summary of the information collected according to the province and source of forecast information. Forecast usage does not always add up to number interviewed as some participants failed to answer this question. Forecast usage: TK, traditional knowledge

\begin{tabular}{|c|c|c|c|c|c|c|c|c|c|}
\hline Country & Province & $\begin{array}{l}\text { Number } \\
\text { interviewed }\end{array}$ & $\begin{array}{l}\text { Forecast } \\
\text { usage }\end{array}$ & $\begin{array}{l}\text { Age category } \\
31-50\end{array}$ & $\begin{array}{l}\text { Age category } \\
51-70\end{array}$ & $\begin{array}{l}\text { Age category } \\
>70\end{array}$ & $\begin{array}{l}\text { Age category } \\
\text { unknown }\end{array}$ & Male & Female \\
\hline \multirow[t]{8}{*}{ Niue } & \multirow[t]{4}{*}{-} & \multirow[t]{4}{*}{41} & TK & 1 & 1 & 3 & 0 & 4 & 1 \\
\hline & & & Met & 0 & 2 & 0 & 0 & 0 & 2 \\
\hline & & & Both & 2 & 12 & 18 & 0 & 16 & 16 \\
\hline & & & None & 0 & 0 & 2 & 0 & 1 & 1 \\
\hline & Total Niue: & 41 & & 3 & 15 & 23 & 0 & 21 & 20 \\
\hline & TK 5 & & & & & & & & \\
\hline & Met 2 & & & & & & & & \\
\hline & Both 32 & & & & & & & & \\
\hline \multirow[t]{23}{*}{ Solomon Islands } & \multirow[t]{3}{*}{ Guadalcanal } & \multirow[t]{3}{*}{3} & $\mathrm{TK}$ & 0 & 0 & 0 & 0 & 0 & 0 \\
\hline & & & Met & 0 & 0 & 0 & 0 & 0 & 0 \\
\hline & & & Both & 3 & 0 & 0 & 0 & 1 & 2 \\
\hline & \multirow[t]{3}{*}{ Central } & \multirow[t]{3}{*}{30} & TK & 0 & 2 & 5 & 0 & 5 & 2 \\
\hline & & & Met & 0 & 0 & 0 & 0 & 0 & 0 \\
\hline & & & Both & 1 & 4 & 18 & 0 & 16 & 7 \\
\hline & \multirow[t]{3}{*}{ Makira } & \multirow[t]{3}{*}{1} & TK & 0 & 0 & 0 & 0 & 0 & 0 \\
\hline & & & Met & 0 & 0 & 0 & 0 & 0 & 0 \\
\hline & & & Both & 1 & 0 & 0 & 0 & 1 & 0 \\
\hline & \multirow[t]{3}{*}{ Malaita } & \multirow[t]{3}{*}{25} & TK & 2 & 1 & 0 & 1 & 2 & 2 \\
\hline & & & Met & 2 & 1 & 0 & 0 & 2 & 1 \\
\hline & & & Both & 6 & 6 & 3 & 3 & 11 & 7 \\
\hline & \multirow{3}{*}{$\begin{array}{l}\text { Western } \\
\text { Province }\end{array}$} & \multirow[t]{3}{*}{1} & $\mathrm{TK}$ & 0 & 0 & 0 & 0 & 0 & 0 \\
\hline & & & Met & 0 & 0 & 0 & 0 & 0 & 0 \\
\hline & & & Both & 1 & 0 & 0 & 0 & 1 & 0 \\
\hline & \multirow[t]{3}{*}{ Unknown } & 3 & TK & 0 & 0 & 0 & 0 & - & - \\
\hline & & & Met & 0 & 0 & 0 & 0 & - & - \\
\hline & & & Both & 0 & 0 & 0 & 3 & - & - \\
\hline & Total & 63 & & 16 & 14 & 26 & 7 & 39 & 21 \\
\hline & Solomon: & & & & & & & & \\
\hline & TK 11 & & & & & & & & \\
\hline & Met 3 & & & & & & & & \\
\hline & Both 49 & & & & & & & & \\
\hline Tonga & Tongatapu & 22 & $\mathrm{TK}$ & 0 & 0 & 1 & 0 & 1 & 0 \\
\hline & & & Met & 1 & 0 & 0 & 0 & 0 & 1 \\
\hline & & & Both & 3 & 12 & 4 & 0 & 15 & 4 \\
\hline & & & None & 0 & 1 & 0 & 0 & 0 & 1 \\
\hline & Ha'apai & 5 & $\mathrm{TK}$ & 0 & 0 & 0 & 0 & 0 & 0 \\
\hline & & & Met & 0 & 0 & 0 & 0 & 0 & 0 \\
\hline & & & Both & 1 & 1 & 2 & 0 & 3 & 1 \\
\hline & Niua & 7 & TK & 0 & 0 & 0 & 0 & 0 & 0 \\
\hline & & & Met & 0 & 0 & 1 & 0 & 1 & 0 \\
\hline & & & Both & 0 & 1 & 5 & 0 & 6 & 0 \\
\hline & Vava'u & 3 & TK & 0 & 0 & 0 & 0 & 0 & 0 \\
\hline & & & Met & 1 & 1 & 1 & 0 & 3 & 0 \\
\hline & & & Both & 0 & 0 & 0 & 0 & 0 & 0 \\
\hline & Total Tonga: & 36 & & 6 & 16 & 14 & 0 & 29 & 8 \\
\hline & TK 1 & & & & & & & & \\
\hline & Met 5 & & & & & & & & \\
\hline & Both 30 & & & & & & & & \\
\hline Vanuatu & Torba & 24 & TK & 6 & 6 & 3 & 1 & 14 & 2 \\
\hline & & & Met & 0 & 0 & 0 & 0 & 0 & 0 \\
\hline & & & Both & 6 & 2 & 0 & 0 & 8 & 0 \\
\hline & Sanma & 3 & TK & & & & & & \\
\hline & & & Met & & & & & & \\
\hline & & & Both & & & & & & \\
\hline & Penama & 14 & TK & 1 & 0 & 0 & 0 & 0 & 1 \\
\hline & & & Met & 1 & 1 & 0 & 0 & 2 & 0 \\
\hline & & & Both & 0 & 4 & 3 & 0 & 6 & 1 \\
\hline
\end{tabular}

forecast only; Met, only use contemporary forecasts from the meteorological service; Both, a mix of TK and Met forecasts; None, did not seek either contemporary or TK forecasts 
Table 1 (continued)

\begin{tabular}{|c|c|c|c|c|c|c|c|c|c|}
\hline Country & Province & $\begin{array}{l}\text { Number } \\
\text { interviewed }\end{array}$ & $\begin{array}{l}\text { Forecast } \\
\text { usage }\end{array}$ & $\begin{array}{l}\text { Age category } \\
31-50\end{array}$ & $\begin{array}{l}\text { Age category } \\
51-70\end{array}$ & $\begin{array}{l}\text { Age category } \\
>70\end{array}$ & $\begin{array}{l}\text { Age category } \\
\text { unknown }\end{array}$ & Male & Female \\
\hline & \multirow[t]{3}{*}{ Malampa } & \multirow[t]{3}{*}{15} & $\mathrm{TK}$ & 0 & 1 & 0 & 0 & 1 & 0 \\
\hline & & & Met & 0 & 0 & 0 & 0 & 0 & 0 \\
\hline & & & Both & 0 & 11 & 3 & 0 & 12 & 2 \\
\hline & \multirow[t]{3}{*}{ Shefa } & \multirow[t]{3}{*}{3} & TK & 0 & 0 & 0 & 0 & 0 & 0 \\
\hline & & & Met & 0 & 0 & 0 & 0 & 0 & 0 \\
\hline & & & Both & 1 & 0 & 0 & 0 & 1 & 0 \\
\hline & \multirow[t]{3}{*}{ Tafea } & \multirow[t]{3}{*}{48} & TK & 3 & 14 & 2 & 2 & 18 & 3 \\
\hline & & & Met & 1 & 0 & 0 & 0 & 1 & 0 \\
\hline & & & Both & 12 & 6 & 0 & 0 & 18 & 0 \\
\hline & Unknown & 7 & & & & & & & \\
\hline & Total & 114 & & 31 & 45 & 11 & 3 & 81 & 9 \\
\hline & Vanuatu: & & & & & & & & \\
\hline & TK 39 & & & & & & & & \\
\hline & Met 3 & & & & & & & & \\
\hline & Both 48 & & & & & & & & \\
\hline \multirow[t]{4}{*}{ Total Respondents: } & & 254 & & 56 & 90 & 74 & 10 & 170 & 58 \\
\hline & TK 56 & & & & & & & & \\
\hline & Met 13 & & & & & & & & \\
\hline & Both 159 & & & & & & & & \\
\hline
\end{tabular}

rural communities elsewhere (e.g. Zimbabwe, Patt et al. 2005; Tanzania, Mahoo et al. 2013; Chengula and Nyambo 2017; India, Tall et al. 2014; sub-Saharan Africa, Masinde 2015). However, more people now have access to mobile phones than radios in many Pacific Islands (Noske-Turner et al. 2014). In Samoa, mobile phone coverage is around $90 \%$ and high literacy rates mean text messages may be an effective way of warning about extreme events (SPREP 2016b). However, similar network coverage in Vanuatu may not translate to similar effectiveness due, in part, to lower phone ownership rates, although the information from the text-based warnings may reach a large proportion of the population through informal networks (Handmer and Iveson 2017). In Niue, mobile phone penetration is lower, but free public Wi-Fi results in Internet access rates being considerably higher than many other Pacific countries (Noske-Turner et al. 2014). Preferred approaches to accessing information also differ generationally, with older generations less likely to hear about warnings via social media or the Internet (Noske-Turner et al. 2014). Hence, the mechanisms of the forecast of delivery often determine whether it is received and utilised. This includes consideration of using language and context that are familiar to the intended audience, increasing the likelihood that the message is understood (Walshe and Nunn 2012; Mahoo et al. 2013; Janif 2014; Jiri et al. 2016).

However, having access to contemporary forecast products is no guarantee that they will be accepted and used. For example, in the southwestern highlands of Tanzania awareness of contemporary climate forecasts is high $(96 \%)$ but this did not translate into a similar level of usage, with only $58 \%$ using the forecasts for planning agricultural activities (Chang'a et al. 2010; 40\% used contemporary forecasts in Chengula and Nyambo 2017). This difference has been explained by NMS forecasts being either inherently mistrusted, having a perceived lack of forecast skill, being difficult to understand or they felt that the reliability of their TK-based forecasts was sufficient and no further forecast information was required (e.g. Patt et al. 2005; Ouma 2009; Masinde 2015; SPREP 2016a). Hence, contemporary forecasts may play a greater role for these communities in complementing, rather than replacing, TK-based forecasts (Luseno et al. 2002; Mercer et al. 2007; Mahoo et al. 2013; Chengula and Nyambo 2017; Plotz et al. 2017; Plotz and Chambers 2017). Using a participatory approach to forecast generation and communication, where community members become agents not just consumers, can help build the forecast credibility and salience, and is likely to lead to greater usage (Patt et al. 2005; Jiri et al. 2016; Plotz et al. 2017). An example of how this has worked in practice is the successful generation of the joint (NMS and traditional knowledge expert) seasonal outlooks in Africa (Mahoo et al. 2013; Ouma et al. 2015; Malsale et al. 2018).

Knowledge and usage of TK for weather and climate forecasting is also expected to differ by location and by age. In southwestern Viti Levu and Vatulele, Fiji, fewer than $50 \%$ of the people interviewed had knowledge of traditional indicators, with many of the stories relating to signs of extreme weather events, such as cyclones (Janif 2014). Usage, and hence awareness, of TK was much higher in the Melanesian countries, Vanuatu and the Solomon Islands (>94\%; this study), than in Polynesia (Niue and Tonga). Locational differences in the reliance of rural communities on TK for weather and climate forecasting have been observed elsewhere, e.g. Africa, southern Ethiopia and northern Kenya; but, as was seen in this study, all sites had a much 
higher usage of TK compared to contemporary forecast information (Luseno et al. 2002). These geographic differences may be influenced by the remoteness of the villages surveyed, the intactness of their traditional cultural practices, the processes used to identify whom to interview, etc. For example, very few individuals we interviewed resided in capital cities or major towns potentially influencing their awareness of and ability to access contemporary forecasts. TK is often used more by older generations (this study; King et al. 2008; Janif et al. 2016; Handmer and Iveson 2017). For younger generations, contemporary scientific knowledge is starting to replace TK practices and this can produce tension in some villages (Janif et al. 2016). There is a concern that this loss of TK has the potential to reduce resilience to impending natural disasters (Mercer et al. 2007; Janif 2014; Handmer and Iveson 2017). This may, at least partly, be overcome by wider recognition of the value of TK, e.g. government or NGO, which could potentially re-engage younger generations (Janif et al. 2016; Malsale et al. 2018).

In ni-Vanuatu society, people with the highest status, who are generally older males, hold the greatest amount of TK, as well as influencing who and how it can be assessed (Walshe and Nunn 2012). Chiefs, and community meetings, directed who should be approached to share their TK and this resulted in more males being interviewed. The Vanuatu project team consisted mainly of males, due to in-country protocols when travelling to many of the remote communities. This potentially skewed the gender balance of those interviewed, as did the village allocation of duties resulting in females generally being too busy to be disturbed for interviews.

Recent extreme events in the Pacific have shown that selfreliant communities, with knowledge of traditional ways of forecasting and responding to extreme events, experienced fewer negative impacts, including lower socioeconomic impacts and death tolls, particularly when combined with reliable, timely and informative contemporary warnings (Walshe and Nunn 2012; Janif et al. 2016; Handmer and Iveson 2017). For many Pacific communities, traditional forecast knowledge remains widely used, particularly amongst the older generations, and this information may be used in conjunction with contemporary forecasts and warnings, particularly in periods surrounding extreme events. This study highlights the need to better understand local community forecast usage, including barriers and preferences for receiving forecasts, and that effective risk reduction, warnings and responses should consider both TK and contemporary systems. Doing so can lead to wider recognition and resurgence in the use of relevant TK. Government agencies, such as NMSs, by incorporating and acknowledging this information, will be better placed to disseminate messages using appropriate media, language and cultural considerations.
Acknowledgments This work was conducted under the Australian Department of Foreign Affairs and Trade funded Climate and Oceans Support Program in the Pacific. We would like to acknowledge our Pacific project partners who conducted the community consultations and the willingness of the communities to share their knowledge with them. We appreciate comments on earlier drafts by Catherine Ganter and Salesa Nihmei and two anonymous reviewers.

Open Access This article is distributed under the terms of the Creative Commons Attribution 4.0 International License (http:// creativecommons.org/licenses/by/4.0/), which permits unrestricted use, distribution, and reproduction in any medium, provided you give appropriate credit to the original author(s) and the source, provide a link to the Creative Commons license, and indicate if changes were made.

\section{References}

Brahy N (2006) The contribution of databases and customary law to the protection of traditional knowledge. Int Soc Sci J 58:259-282 https://onlinelibrary.wiley.com/doi/abs/10.1111/j.1468-2451.2006. 00618.x. https://doi.org/10.1111/j.1468-2451.2006.00618.x

Chambers LE, Plotz RD, Dossis T, Hiriasia DH, Malsale P, Martin DJ, Mitiepo R, Tahera K, Tofaeono T (2017) A database for traditional knowledge of weather and climate in the Pacific. Meteorol Appl 24: 491-502. https://doi.org/10.1002/met.1648

Chand SS, Chambers LE, Waiwai M, Malsale P, Thompson E (2014) Indigenous knowledge for environmental prediction in Pacific island countries. Weather Clim Soc 6:445-450. https://doi.org/10. 1175/WCAS-D-13-00053.1

Chang'a LB, Yanda PZ, Ngana J (2010) Indigenous knowledge in seasonal rainfall prediction in Tanzania: a case of the South-Western Highland of Tanzania. J Geogr Reg Plan 3:66-72 http://hdl.handle. net/10625/48748. Accessed 19 Dec 2018

Chengula F, Nyambo B (2017) Dissemination of agricultural weather forecasts under weather and climate variability: a case of the smallholder farmers in Moshi rural district, Tanzania. Int J Agric Educ Ext 3:48-57

Gilles JL, Valdivia C (2009) Local forecast communication in the Altiplano. BAMS 90:85-91. https://doi.org/10.1175/ 2008BAMS2183.1

Handmer J, Iveson H (2017) Cyclone Pam in Vanuatu: learning from the low death toll. Aust J Emerg Manag 32:60-65

Janif SZ (2014) Assessing the value of oral narratives to build resilience to climate change - Case study of southwestern coast of Viti Levu and the islands of Vatulele, Fiji. Masters Thesis, University of the South Pacific

Janif SZ, Nunn PD, Geraghty P, Aalbersberg W, Thomas FR, Camailakeba M (2016) Value of traditional oral narratives in building climate-change resilience: insights from rural communities in Fiji. Ecol Soc 21:7. https://doi.org/10.5751/ES-08100210207

Jiri O, Mafongoya PL, Mubaya C, Mafongoya O (2016) Seasonal climate prediction and adaptation using indigenous knowledge systems in agriculture systems in southern Africa: a review. J Agric Sci 8:156172. https://doi.org/10.5539/jas.v8n5p156

King DNT, Skipper A, Tawhai WB (2008) Māori environmental knowledge of local weather and climate change in Aotearoa - New Zealand. Clim Chang 90:385-409. https://doi.org/10.1007/s10584007-9372-y

Lefale PF (2010) Ua 'afa le Aso stormy weather today: traditional ecological knowledge of weather and climate. The Samoa experience. 
Clim Chang 100:317-335. https://doi.org/10.1007/s10584-0099722-z

Lemos MC, Dilling L (2007) Equity in forecasting climate: can science save the world's poor? Sci Public Policy 34:109-116. https://doi. org/10.3152/030234207X190964

Lobo C, Chattopadhyay N, Rao KV (2017) Making smallholder farming climate-smart: integrated agrometeorological services. Econ Polit Wkly LII(1):53-58

Luseno WK, McPeak JG, Barrett CB, Little PD, Gebru G (2002) Assessing the value of climate forecast information for pastoralists: evidence from southern Ethiopia and northern Kenya. Final project report to the International Research Institute for Climate Prediction, Columbia University, USA, and to the Department of Range

Mahoo H, Mbungu W, Rwehumbiza F, Mpeta E, Yonah I, Recha J, Radeny M, Kinyangi J (2013) Seasonal weather forecasting: integration of indigenous and scientific knowledge. Proceedings AISA Workshop on Agricultural Innovation Systems in Africa, Nairobi, 29-31 May 2013

Malsale P, Sanau N, Tofaeono TI, Kavisi Z, Willy A, Mitiepo R, Lui S, Chambers LE, Plotz RD (2018) Protocols and partnerships for engaging Pacific Island communities in the collection and use of traditional climate knowledge. BAMS 99:2471-2489. https://doi.org/ 10.1175/BAMS-D-17-0163.1

Masinde M (2015) An innovative drought early warning system for subSaharan Africa: integrating modern and indigenous approaches. Afr J Sci 7:8-25. https://doi.org/10.1080/20421338.2014.971558

Mercer J, Dominey-Howes D, Kelman I, Lloyd K (2007) The potential for combining indigenous and western knowledge in reducing vulnerability to environmental hazards in small island developing states. Environ Hazards 7:245-256. https://doi.org/10.1016/j. envhaz.2006.11.001

Muse C, Muse S (1982) The birds and birdlore of Samoa: O manu ma tala'aga o manu o samoa. Pioneer Press. 156pp. ISBN-13: 9780936546056

Nalau J, Becken S, Noakes S, Mackey B (2017) Mapping tourism stakeholders' weather and climate information seeking behaviour in Fiji. Weather Clim Soc 9:377-391. https://doi.org/10.1175/WCAS-D16-0078.1

Noske-Turner J, Tacchi J, Horst H, Papoutsaki E (2014) Locating disaster communication in changing communicative ecologies across the Pacific. Aust J Telecommun Digit Econ 2:a66. https://telsoc.org/ ajtde/2014-12-v2-n4/a66. https://doi.org/10.7790/ajtde.v2n4.66

Nurse LA, McLean RF, Agard J, Briguglio LP, Duvat-Magnan V, Pelesikoti N, Tompkins E, Webb A (2014) Small islands. In: Barros VR, Field CB, Dokken DJ, Mastrandrea MD, Mach KJ, Bilir TE, Chatterjee M, Ebi KL, Estrada YO, Genova RC, Girma B, Kissel ES, Levy AN, MacCracken S, Mastrandrea PR, White LL (eds) Climate Change 2014: Impacts, Adaptation, and Vulnerability. Part B: Regional Aspects. Contribution of Working Group II to the Fifth Assessment Report of the Intergovernmental Panel on Climate Change. Cambridge University Press, Cambridge, pp 1613-1654

Ouma G (2009) Linking traditional and modern forecasting in western Kenya. Stories from the Field. https://www.idrc.ca/sites/default/ files/sp/Documents\%20EN/Forecasting-in-western-Kenya.pdf. Accessed 19 December 2018

Ouma G, Ogallo L, Onyango M, Mwangi S, Wayumba G, Mbeva J, Ochieng P, Pala A, Nyamenya P (2015) Community-based climate monitoring services and early warning systems: the case of the
Nganyi community. UNISDR scientific and technical advisory group case studies - 2015. https://www.preventionweb.net/files/ workspace/7935_ogalloera.pdf. Accessed 19 December 2018

Patt A, Suarez P, Gwata C (2005) Effects of seasonal climate forecasts and participatory workshops among subsistence farmers in Zimbabwe. PNAS 102:12623-12628. https://doi.org/10.1073/ pnas.0506125102

Plotz RD, Chambers LE (2017) Linking forecasts and end users: perspectives from a Pacific Aid Program. Bull Aust Meteorol Oceanogr Soc 30:26-29 https:/view.joomag.com/bamos-vol-30-no-4-2017/ 0275708001513862701 ?page $=26$

Plotz RD, Chambers LE, Finn C (2017) The best of both worlds: a decision-making framework for combining traditional and contemporary forecast systems. J Appl Meteorol Climatol 56:2377-2392. https://doi.org/10.1175/JAMC-D-17-0012.1

Seuseu SK, Titimaea MA, Amosa CF, Poulima B, Tofaeono T, Plotz RD, Chambers LE (2013) Linking traditional knowledge with seasonal forecasts in Samoa: lessons from our elders. Greenhouse - the science for climate change conference, Adelaide, 8-11 October 2013

SPREP (2016a) Vanuatu framework for climate services. Commissioned by Secretariat of the Pacific Regional Environment Programme. Prepared by: Tait a and Macara G, National Institute of Water \& Atmospheric Research Ltd (NIWA), New Zealand, in consultation with the Vanuatu Meteorological and Geo-Hazards Department (VMGD), Government of the Republic of Vanuatu. NIWA Client Report no. 2016022WN. 67p

SPREP (2016b) When every minute counts: text messaging (SMS) to alert communities in times of disaster. In: Pacific Islands Meteorological Services in Action: a compendium of climate services case studies, compiled by C Leala-Gale. Secretariat of the Pacific Regional Environment Programme, Apia, Samoa, pp 36-39

Tall A, Hansen J, Jay A, Campbell B, Kinyangi J, Aggarwal PK, Zougmore R (2014) Scaling up climate services for farmers: Mission Possible. Learning from good practice in Africa and South Asia. CCAFS Report No. 13. Copenhagen: CGIAR Research Program on Climate Change, Agriculture and Food Security (CCAFS). www.ccafs.cgiar.org. Accessed 19 Dec 2018

VMGD (2012) National summit to improve understanding on climate, climate change and its impacts on agriculture and land-based sectors. 12-16 March 2012, Luganville, Vanuatu. http://www.nab.vu/ national-summit-improve-understanding-climate-climate-changeand-its-impacts-agriculture-and-land. Accessed 19 March 2018

Walshe RA, Nunn PD (2012) Integration of indigenous knowledge and disaster risk reduction: a case study from Baie Martelli, Pentecost Island, Vanuatu. Int J Disaster Risk Sci 3:185-194. https://doi.org/ 10.1007/s13753-012-0019-x

Zuma-Netshiukhwi G, Stigter K, Walker S (2013) Use of traditional weather/climate knowledge by farmers in the South-Western Free State of South Africa: agrometeorological learning by scientists. Atmosphere 4:383-410. https://doi.org/10.3390/atmos4040383

Publisher's note Springer Nature remains neutral with regard to jurisdictional claims in published maps and institutional affiliations. 


\section{Affiliations}

Lynda Chambers $^{1} \cdot$ Siosinamele Lui $^{2} \cdot$ Roan Plotz ${ }^{1,3} \cdot$ David Hiriasia $^{4} \cdot$ Philip Malsale $^{2,5}$. Rossylynn Pulehetoa-Mitiepo ${ }^{6} \cdot$ Melinda Natapei $^{5} \cdot$ Noel Sanau $^{4} \cdot$ Mike Waiwai $^{5,7} \cdot$ Lloyd Tahani $^{4} \cdot$ Albert Willy $^{5}$. Seluvaia Finaulahi ${ }^{8}$. Falosita Loloa $^{8}$. 'Ofa Fa'anunu ${ }^{8}$

1 Climate and Oceans Support Program in the Pacific, Bureau of Meteorology, GPO Box 1289, Melbourne, Victoria 3001, Australia

2 Secretariat of the Pacific Regional Environment Programme, Apia, Samoa

3 Institute of Sustainable Industries and Liveable Cities, Victoria University, Melbourne, Australia

4 Solomon Islands Meteorological Service, Honiara, Solomon Islands
5 Vanuatu Meteorology and Geo-Hazards Department, Port Vila, Vanuatu

6 Niue Meteorological Service, Alofi, Niue

7 Ministry of Climate Change, Port Vila, Vanuatu

8 Tonga Meteorological Services, Nuku'alofa, Tonga 